\title{
Women's Empowerment Revisited: In Contemporary Societies of India
}

\author{
Sameena Zahoor Mir
}

Assistant Professor, AKK New Law Academy, Pune, Maharashtra, India. Corresponding Author's Email: sameenamir02@gmail.com

\begin{abstract}
Although numerous female writers have researched there has become a topic of great concern lately, their piece analyzes the changing perceptions of women's writing. The pattern is moderately dependable all-over the stand for enlightenment. Their research examines the theoretical basis of the evaluation of female reinforcement and designs the results to analyze the current clue situation identified in the most recent evaluation. I will not only propose and present a new set of indicators, as the approach is intended to replace the traditional methods. It also examines how friendly, financial and political changes affect assessments of women's empowerment, and discusses the effects of assessing women's empowerment in other settings.
\end{abstract}

Key words: Women-Empowerment, Social Change, Admiration, Financial Assessment, Status of women.

\section{Introduction}

Studying female reinforcement, empowerment advises perseverance and the involvement of those (women) who appear to have special communication. Women's empowerment is the most important component of a country's long-term growth. For a long time, Indian women were considered a symbol of status, power and knowledge. Today, the accomplishments of Indian women in some disciplines show that they have admirably earned their position. Further research shows that the massive presence of certain very connected and chosen women has now become a fundamental feature of Indian society. Dissident activists have strengthened the indications and expected to play a major role in addressing many societal problems. They have all shown a high level of commitment to their respective controls.

\section{Social Empowerment}

Aruna Roy is known for her efforts to fight corruption and promote government transparency. Her surroundings had an impact on her life; although her mother encouraged her to be independent, her father gave her a strong sense of social responsibility. Aruna began teaching at the Aurabindo Ashram in Pondicherry and Indraprasta College in Delhi. Even so, She realized that teaching wasn't her passion when he planned to become an administrative clerk. Aruna Roy 1967 she passed the Indian Administrative Service (IAS) exam. Mazdoor Kisan Shakti Sangathan, a social and mass development for workers and workers, sees Aruna as a key person. She played a key role in the passage of the Access to Information Act 2005. Reliable Sources Aruna has received multiple awards for her contribution to society. Aruna was named one of Time Magazine's "100 Most Influential People in the World" in 2011.

Medha Patkar has shown a keen interest in open engagements since she was a child. As the daughter of a workers' association expert, she observes the problems of the poor and is determined to help them. Her father was a key figure in India's economic development, and her mother founded Swadar, an organization that helps disadvantaged women and helps them with education.

This is an Open Access article distributed under the terms of the Creative Commons Attribution CC BY license (http://creativecommons.org/licenses/by/4.0/), which permits unrestricted reuse, distribution, and reproduction in any medium, provided the original work is properly cited.

(Received 03 August 2021; Revised 06 September 2021; Accepted 27 September 2021) 


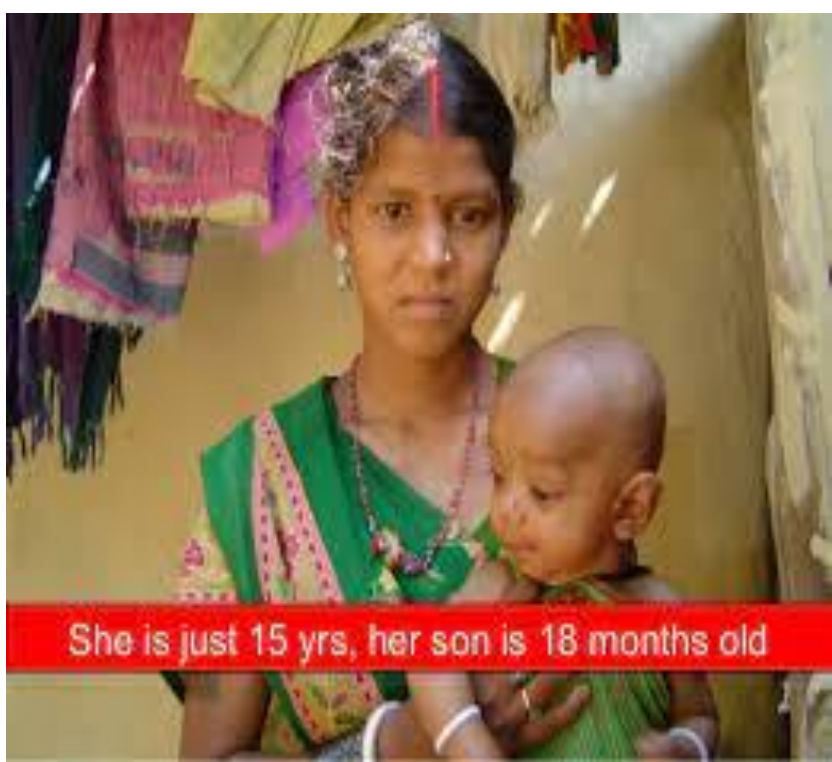

Figure 1: Un-empowered women

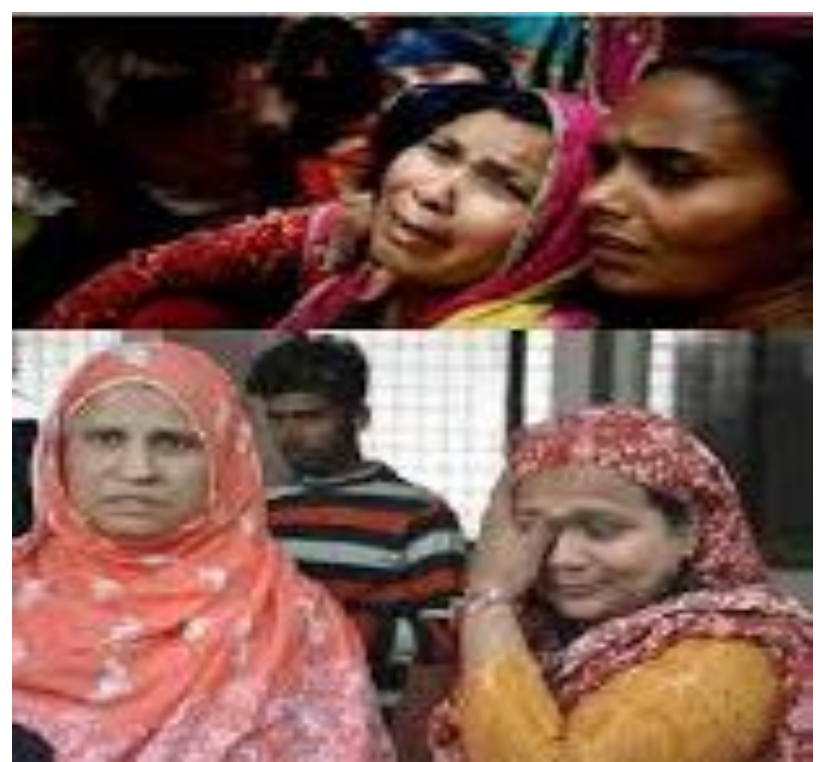

Figure 2: Un-empowered women

Source; Institute of South Asian Institute (images)

Pramila Nesargi is a lawyer from India who advocates women's rights. She was influenced by her own relatives. Her mother became a fighter, her father gave her opportunities. She obtained a criminal diploma and at the age of 22 thought about the profession of lawyer. Domestic violence, child labor, commercial misconduct and the care of prisoners were subjects of her investigation. She has also worked with many not-for-profit firms to help them organize their activities. Her appointment as chairman of the Karnataka Bar Council is widespread considering it is by far the first time a woman has filled the post in the next 50 years. Pramila has addressed many topics including aggressive, controversial, and well-researched topics. Akanksha became the base through Shaheen Mistri, the author of Teaching for India. Her determination to use good academic judgment has earned her a well-deserved reputation. To her dismay, she quickly learned that the people in the slums of the metropolis of Mumbai were not prepared to compete in India's skills and organization-oriented labor market. The Akanksha Center became a Mounted in 1989 to provide afterfaculty tutoring. When Shaheen came to Teach for India in 2008, she saw an opportunity to expand her impact and make greater progress. Seven countries are currently active in the education and training of people from different backgrounds. Accepting the idea that you may be helpless is one of the maximum approaches typically said to leaving authority behind. Every citizen of India has the opportunity to help shape the country's better future. "At the end of the day, don't forget that you are a person, don't forget that you are a mother, a wife and a daughter."....... "Indra Nooyi"

\section{Political Empowerment}

Political activation facilitates the implementation of strategies that promote leadership and the unification of women in both official and informal settings. Options include government action on minorities in society and initiatives to monitor the number of women in dynamic and authoritative roles. As of 2017, a comparable proportion of women in the lower and unicameral seats in parliament were around $23 \%$ (1). It was also proposed to expand women's democratic rights, give those more opportunities to express themselves and allow them to run with a real chance of victory. Since they often work in the household with childcare and selfconstruction projects, women have less optimal opportunities to enter the labor market and work for their organizations. Approaches that differ from cases, methods that improve women's medical care 
and tactics that allow women to control money are examples of arrangements that increase women's power in the household (2). In any case, affiliation is not limited to legal matters. It may require participation at home, in school, and the ability to make independent judgments. Any theory would argue that the family organizing powers and duties must be completed before major political support can be mobilized (3).

Several people, including Jayalalitha, believe women have a choice: The politicized \"Amma\" brand (politics) Jayalalitha is known for her seedy and opulent lifestyle as an entertainer who later became a government official. Indira Gandhi is considered one of the most powerful politicians in India (4). In the competition for notable political pioneers, Jayalalithaa must not be forgotten. With the help of her friends, Jayalalithaa maintains control of Tamil Nadu, as does Gandhi as India's first female leader. Although he was sentenced to four years in prison in September 2014 (5), Her friends refused to release her as she was involved in a withdrawal scandal, instead fighting the decision and crying bitter tears for her 'amma'. Similar followers cried for joy when she received a clean slip from the Karnataka High Court. They also see her as a \"goddess \" and she has established a brand image of Amma. As a result, an amazing revelation regarding his power is revealed. Whether attention is paid to ruling nature or greed is a different matter (6). They place great value on government support and coordinated dynamics, as well as the ability to inject capital into the financial sector while participating in the financial dynamics.

\section{Economic Empowerment}

The interaction by which individuals manage their own lives, networks, and social orders is known as empowerment. People are motivated by the thought of approaching infinite freedoms in areas such as education, employment and lifestyle. Feeling empowered to make your own decisions gives you a sense of empowerment. Empowering women includes improving their status through education, increasing awareness, knowledge and preparation, and in any case offering self-defense training. Women's emancipation is linked to the empowerment and opportunity for women to make amazing choices despite the myriad of obstacles in society (7).
Alternatively, for women, the approach to categorizing generalizations of gender identity is what enables them to consider imagined possible outcomes that were not previously available to them. There are many criteria used to characterize women's equilibrium, such as the idea that one must start in a debilitated state in order to become empowered. Strengthening comes from a place of trust. Surprisingly, instead of relying on an outside source for reinforcement, find it yourself. According to several surveys, people's flexibility to make important life decisions and the ability to overcome them are among the sources of empowerment. After all, as stated earlier, both strengthening and weakening are emotional to others; so empowerment is more of a means than an end result.

In the areas of development and finance, the empowerment of women is a prominent topic of discussion. It can also refer to attitudes towards other marginalized sexual orientations in a particular political or social context. Women's financial empowerment relates to their ability to value and benefit from assets, resources, compensation, and their own time, as well as their ability to manage risk and improve their financial status and success. Despite the fact that different formulations are widely used, the broader and more real nature of strengthening gender orientation applies to individuals of any gender, underscoring the distinction between science and gender as a skill. In India, the number of women in business is growing and one of them has overcome the hurdles of gaining prominence in its industry. Each of their excursions serves as a catalyst to break through the glass ceiling and push our boundaries (8).

"Take more risks in your life. If you win, you will lead. If you fail, you will lead!" "Swami Viveknanda"

Kiran Mazumdar-Shaw was named one of the 100 most influential women in the world by TIME magazine and is considered a pioneer in biotechnology. She is your gatekeeper. Kiran Mazumdar-Shaw was named World Entrepreneur of the Year 2020 by EY, making it the third Indian and second woman to receive the award. She talks about her business problems. 


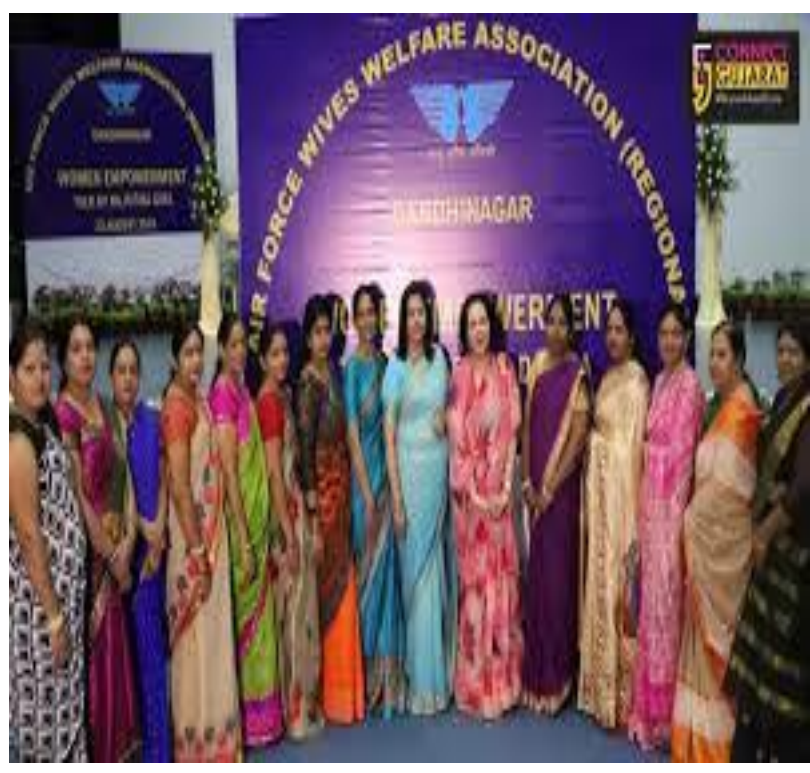

Figure 3: Empowered women

Source; Institute of South Asian Institute (images)

Women's empowerment programs and tactics can benefit entire nations, organizations, networks, and groups. Empowering the role of women is vital to a country's progress as it increases the quantity and variety of HR available for progress. Strengthening fundamental freedoms and progress is one of the most difficult procedural tasks (9).

Empowering women and achieving gender parity is essential to the long-term growth of our society. Many pioneers and wise people around the world have said that sustainable progress is impossible without gender equality and the empowerment of women. Nature conservation, social and economic change and the empowerment of women are aspects of sustainable development.

\section{Sports Empowerment}

The women are always been challenged for the innovation headed by the Patriarchal societies. The Sport is being the one where the opportunities for the women have knocked the passion to not only promote individually but globally as well. Which approve the self-confidence, leadership and teamwork skills to achieve the well-known names in the existing gender assessed societies (10). The sports need a huge strength and the male accessing societies have fall of for the success and the continuous inspiration for

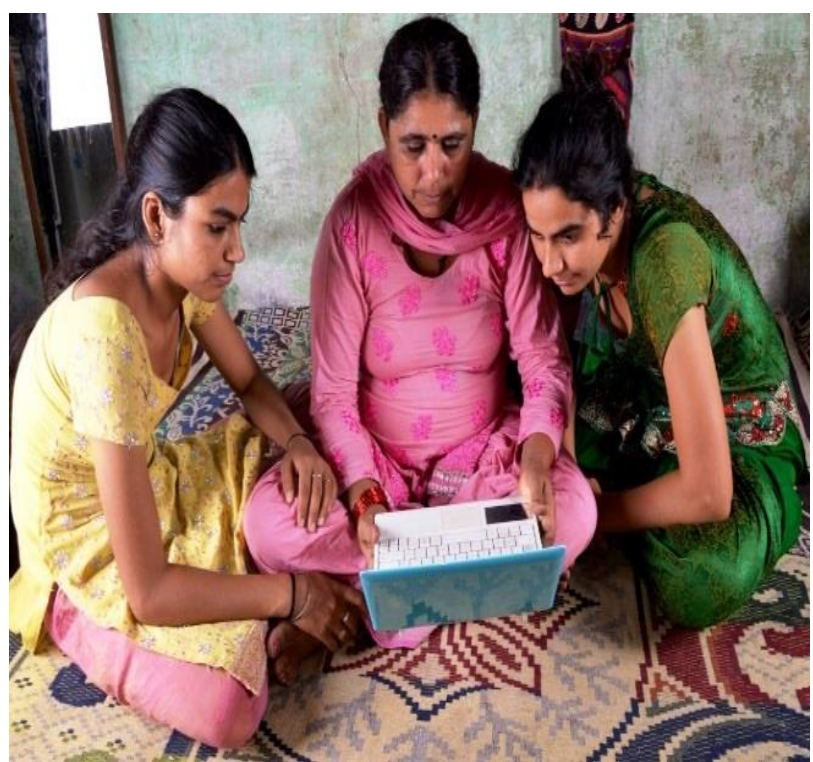

Figure 4: Empowered women

other women around. This has break down the gender barriers and discriminations.

The women in India and Indian women in sports despite of Boxing, Wrestling, Tennis, Cricket and what not but things were not so easy, because the progress of men in the sports and their national pride with the financial strength have not interruption the spirit of women to go shoulder to shoulder and achieve the same. The Indian women in sports have enumerated their names in the international sports by winning the auspicious games. In the Olympics Asian Games, the names like Mary Kom as "Magnificent Mary" won the Gold Medal in 2014 in Incheon. The freestyle name in the women wrestler Geeta Phogat nibble the Gold Medal in Common wealth Games 2010. The international women's sports have fascinated the names of the women and the shining stars like Saina Nehwal accomplished the Olympic Medal. In the continuous winning margin in the current 2021 the victory is remarkable with the Olympic medals in the account of Lovlina Borgohain, Mirabai Chanu and PV Sindhu (11).

Nevertheless the G.O.A.T (greatest of all the time) is in continuity, the mixed set of benchmarks on proposal of many other attitudes and perspectives. 
"People used to say that boxing is for men and not for women and I thought I will show them some day. I promised myself and proved myself " ...... "Mary Kom"

\section{Conclusions}

The main achievements, including contributions may be summarized as follows. In the course of their work we discovered that it suffers from limitations, some problems remain: bizarre customs and cultural norms persist, women are still underrepresented at all levels of political power, and every fifth woman and every fifth girl between the ages of 15 and 49 is exposed to physical or sexual abuse. As a group, we recognize that investing in and empowering women and young women is known and widespread among those of us who support and contribute to global development projects. We present an overview of the literature related to the work presented here, which includes gender goals and information, as well as a broader equality goal.

It is reportedly becoming increasingly important as women and men protest for fairer treatment in areas ranging from wage differentials to maternity leave regulations. The Sustainable Development Goal is large, bold, and ambitious. It seeks to "achieve gender equality and assist both women and children" across the world. According to the realizations, an ideal woman is perfect and feminine, with a great constitution.

\section{Acknowledgements}

The research behind it would not have been possible without the support of my Husband Sayed Momin Hashimi. His keenness and exacting attention have been an inspiration and kept my work on track from my first encounter to reach out to the goal of writing on empowering the women's situation in different field and to make the draft of this article successful. I am also grateful for the insightful comments offered by the anonymous peer reviewers at Books \& journals. The generosity and expertise of one and all have improved this study in innumerable ways and saved me from many errors; those that inevitably remain are entirely my own responsibility.

\section{Conflict of Interest}

The authors declare that there is no conflict of interests regarding the study or this article.

\section{References}

1.https://opportunity.org/news/blog/2017/03/empowere d-women-change-the-world

2. UNESCO, 2013

3. Gender Equality, Why it Matters, and 2016

4. Government of India. "The Constitution of India". Ministry of Law and Justice. Retrieved 22 March 2014.

5. Constitution of India. "Directive Principles of State Policy". Government of India. Retrieved 22 March 2014.

6. Kabeer, Naila. "Gender equality and women'empoverment: A critical analysis of the third millennium development goal 1." Gender \& Development 13.1 (2005): 13-24.

7. Praveen Rai. "Electoral Participation of Women in India: Key Determinants and Barriers". Economic and Political Weekly. 2011; XVLI (3): 47-55.

8. Rahman Aminur. "Women's Empowerment: Concept and Beyond" (PDF). Global Journal of Human Social Science Sociology \& Culture. 2013; 13 (6): 9. Archived (PDF) from the original on 10 August 2017. Retrieved 11 December 2018.

9. http://www.un.org/press/en/2005/sgsm9738.doc.htm 10. http://www.buissiness-standard.com 2020 11.https://www.indiatoday.in/sports/badminton/story/pv -sindhu-on-winning-2-olympic-medals-feeling-is-yet-tosink-in-1843927-2021-08-22. 